\title{
The Design of the Plate of Longgang Ancient Kiln Heritage Landscape Aesthetic Implication
}

\author{
Zhihua Xu \\ School of Jingdezhen ceramic institute of design art Jingdezhen, 333403, China
}

Keywords: Longgang; Ancient kiln sites; Landscape; Design aesthetics.

\begin{abstract}
Plate of long gang ancient kiln sites is the national 5 a-class tourist scenic spot and Jingdezhen porcelain making craft in one thousand years a microcosm. Beginning, it was made from a porcelain is a typical of traditional and modern landscape design aesthetic van example, disk long gang aesthetic implication of the ancient site focused on its aesthetic and practical, aesthetic and environmental, aesthetic and technology, science and art, etc. Series of the unity of nature and aesthetic implication.
\end{abstract}

\section{Introduction}

The ancient site of the esthetic main body is the ancient site architecture design. Architectural design is aesthetic of aesthetic features and aesthetic value of thought and theory. Architectural design beauty is different from other art forms, it has its own characteristics: (1) the practicability. Architecture must satisfy the human material life and spiritual life of a certain need, any bells or no practical value of the building to give a person with artistic enjoyment. (2) The regional. Architecture and can in various occasions to keep its aesthetic features of literature, music, painting, art forms such as utterly different, it always constitute the important features of the environment. Copy follow one's inclinationsly, regardless of the occasion to bring the result of the absurd. (3) The total effect. Construction has a broad comprehensive ability of art, is a kind of pay attention to the effect of art, both inside and outside environment of the building decoration and art sketch, affiliated to create architectural art image can play a big role, even the critical role. (4) Technical wood. Art of architecture depends on technology, to realize the possibility of building is always by human ability, namely the extent of the architectural technology can achieve. (5) The public. Architecture is a kind of public life phenomenon, in other forms of art wood is often serves as a valuable and meaningful personal emotional expressionism, but it is difficult to be understood in the architectural art. So in a sense, architecture is an art form. The strongest political it often in his own image to reflect the social reality of great themes, and quite profoundly reveals the essence of real life.

Beauty in the ancient site architecture design for all the major characteristic of a building above fully performance, especially the ancient site architecture is practical, technical and regional has its unique artistic value. It is the aesthetic consciousness of life, feelings, interest, ideal) and graceful architectural technology forms () function, structure, form an organic unity. In the construction of the scale, proportion, decoration, color and detail, etc., on the construction form and structure of the components are creative artistic processing; At the same time also make building shape, dimension, the image, the color with the surrounding environment, natural environment and human environment) coordination, has a continuous flow of space overall beauty.

\section{The beauty of art of the ancient site architecture}

Ancient site construction of the beauty of art in its spatial form of order and the diversity of architectural decoration.

\subsection{The ancient site construction sequence space of form beauty}

The ancient site of building space series of form beauty is mainly embodied in the single building magnificent, elegant and symmetrical beauty as well as the single building form beauty and harmonious beauty group sequence. Is the ancient site building exterior plain, energetic and vigorous, 
natural and graceful, elegant and dignified, and building a series of combination scale, space arrangement, scale, and modelling style such as the combination of space form. Space form beauty in summary is harmony, symmetry, scale and proportion. Harmony can produce sense of order; Neat symmetry lets a person feel, calm and steady, and silence. Symmetry is not only the requirement of the building space form, but in the process of the structure, function needs to have a focus on balance, stability and security. Construction symmetry including the left and right sides is symmetrical, symmetrical, all sides symmetry, cyclic symmetric and asymmetric partial and overall, etc. Symmetry is not as neat a drab, its overall has obvious center, thus presents a cohesive and centripetal force of the sense of order, steady, male bonding and solemn style. Is the most obvious in the building?

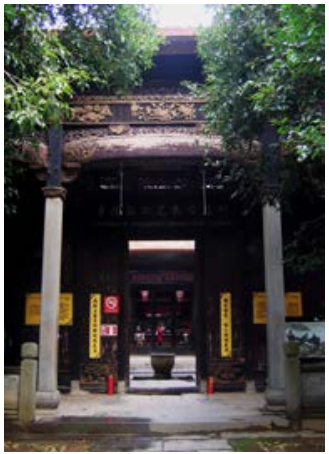

Figure 1 jade ITO the lobby entrance (I photography)

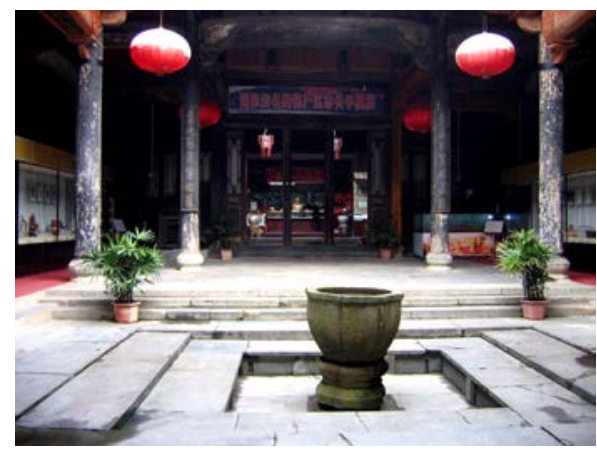

Figure 2 jade ITO internal (I photography)

Plate of longgang ancient site construction of spatial layout has a concise organization law, is emphasized in the orderly axisymmetric layout, left and right sides is symmetrical. Formed in "in" as the characteristics of traditional architectural aesthetic character. The building layout, with horizontal axis and vertical axis, put the body in the position of axis or its balanced on both sides, makes the subject construction often balanced, stable and harmonious. In construction group, with "between" as unit to form single building, again in a single building of the yard, and then to the courtyard as a unit, composed of various forms of group. In terms of individual buildings, with rectangular plane is the most common. The whole building mostly adopt the method of balanced symmetrical, in the courtyard as a unit, along the longitudinal axis and the horizontal axis line to carry on the design layout, with the aid of organic combination and foil of building groups, make the subject building is particularly prominent. The above layout characteristics whether it is big to local-style dwelling houses building, the overall planning of clan ancestral hall; or small to single internal courtyard residence and workshop buildings. All kinds of buildings are built in accordance with the central axis, left and right sides is symmetrical, traditional architecture with the features "in the" aesthetic style, balance, stability and grave feeling to the person. The building layout with horizontal axis and vertical axis as the center, in the courtyard, composed of various forms of group. Such as the clan ancestral temple architecture of axisymmetric is very strict (see figure 1, 2 and 3).

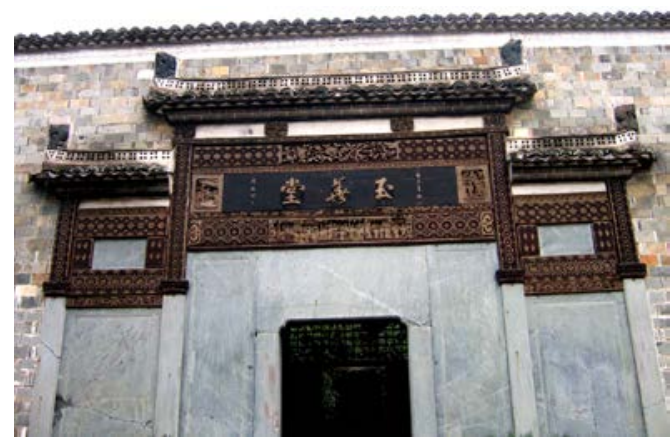

Figure 3 symmetrical jade ITO the lintel(I photography)

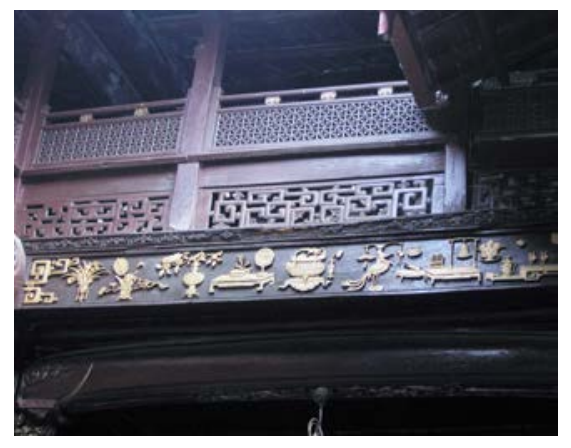

Figure 4 jade ITO floor decoration(I photography) 


\subsection{The beauty of the ancient site building rich variety of decoration}

Building decoration is beautiful expression of building structures, in building the overall appearance, building the model of each part and the creation of color processing and other aspects. Building decoration is a key architectural beauty. Building decoration is the brick, tile, ash, stone materials such as natural color, with different colors, such as glass, glass, paint, by contrast, formation of harmonic, interspersed with penetration techniques such as the construction decoration color. Will be using the technique of painting, sculpture, arts and crafts to building decoration. Ancient site construction of colorful decorative arts, both in terms of form, color, texture, technology skills, composition, and artistic conception has the general features of the Ming and Qing dynasties buildings from the aspects such as the uniqueness of Jingdezhen ceramics workshop building. Mainly displays in: first, decorate means diversity, ancient site construction except paint, paint over with wood oil, sculpture and Mosaic, porcelain. Look from the material with brick, wood, stone, tile, paint, paint, such as copper, tin, the fine combination of production decorative arts and crafts, exquisite, exquisite aesthetic artistic style (see figure 4.5). Such as partition board carved plate doors, Windows and ornamental design, roof grey plastic flowers ridge, stone carvings, beam on the main door along the paint on the painting. Design lifelike, decorate rich variety. Painting decorative theme of plant and geometric lines, antique, flowers, auspicious items such as character, drawing materials fang place mostly drain powder gold, do not use chalk line, and has the drain detail grain powder gold decoration. Tempera paint mostly in stone, Liang fang, eaves in big wooden, eaves use fewer. Is the most distinguished feature of the composition is not blunt symmetric layout, on the symmetric beam pattern shape is not completely consistent, according to Liang fang length with different layout. Painting colour is gorgeous, design is rich. Reflects the architectural technology the perfect combination of art and craft.

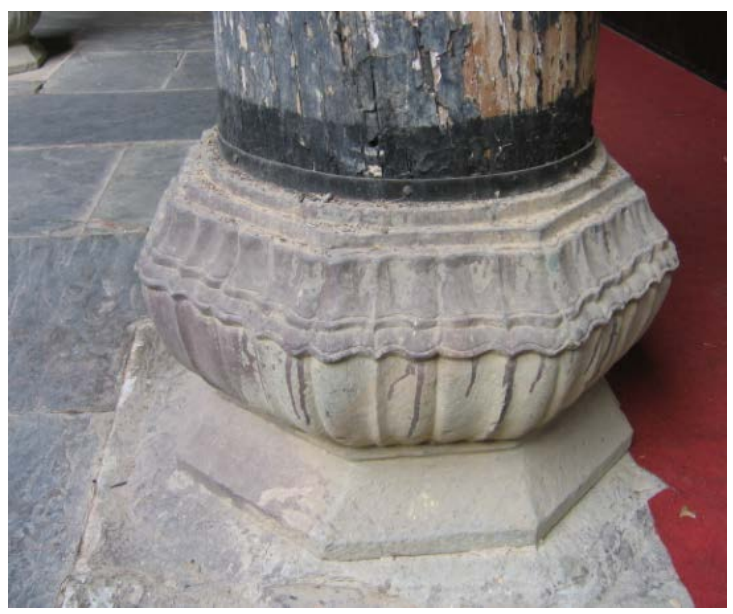

Figure 5 columns(I photography)

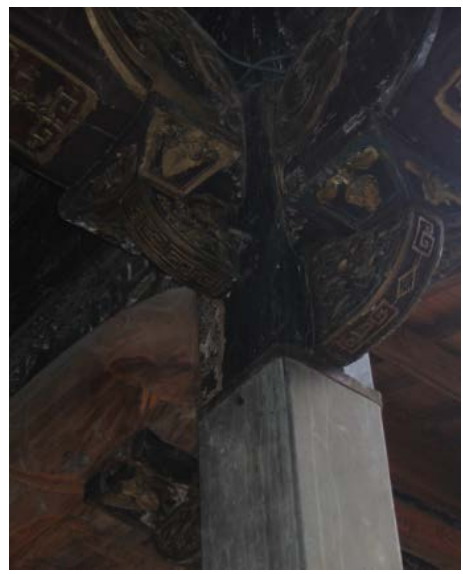

Figure 6 (1) columns(I photography)

Second, unique decorative style, the ancient site building adornment style on the whole, the pursuit of exquisite, delicate artistic effect, with typical jiangnan flavor, brick carvings, wood and furniture furnishings exquisite style harmonious and unified, and closely integrated with porcelain making artistic features, appears to be more perfect. In addition to the overall unity and coordination, a single architectural decoration also each have each characteristic, such as the stone has the beauty of serious; DaWuDing, fly beam stone on the woodcarving has the beauty of elegant; Brick emphasizes the beauty of the stereo space, pay attention to the overall layout, image depict stressed body quickly, straightforward, slightly, plain and simple style, the composition is simple, emphasis on symmetry, the pursuit of numerous fine level change, abound adornment concise beauty (see figure 7). 


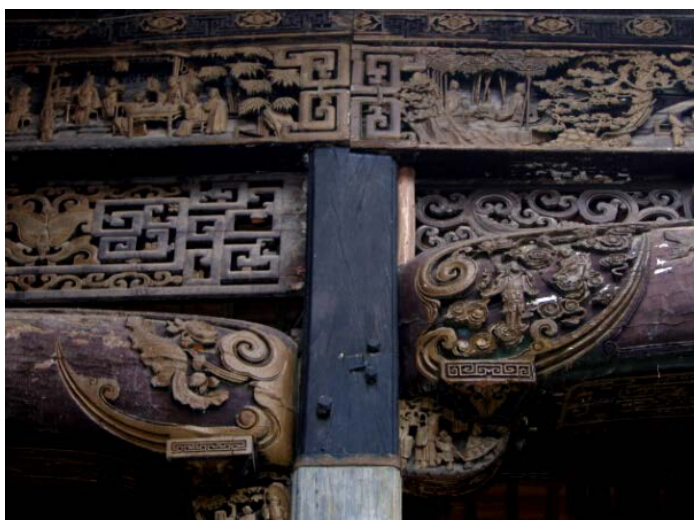

Figure 7 jade ITO beam along the adornment of carve patterns or designs on woodwork(I photography)

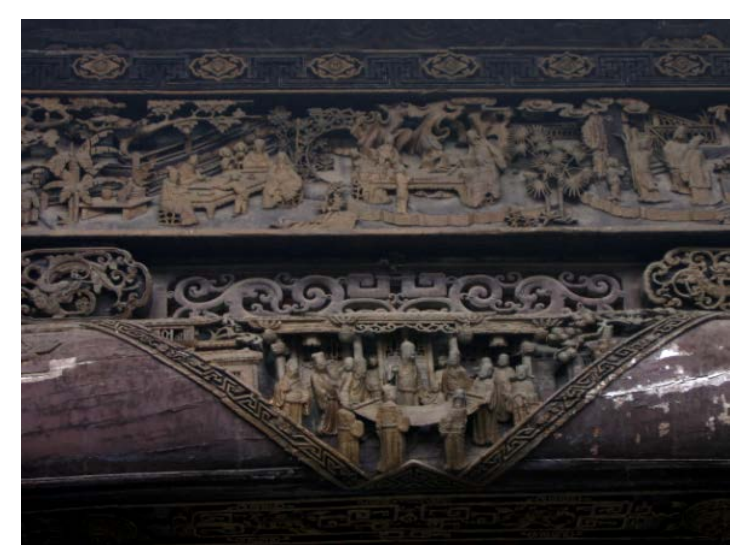

Figure 8 jade ITO beam along the adornment of carve patterns or designs on woodwork(I photography)

Third, exquisite decorative techniques, decoration techniques in using various techniques, such as carved, engraved, plastic, painting seiko fine carving. Painting decorative color is gorgeous, dense part adopts gold form, show a luxurious. Painting drain powder, gold technique is a very important procedure drain powder layer upon layer of plastic can form the stereo sense is very strong lines or some relief of the image, and then on the gold. Have flat carving, carving techniques valuable.such handiwork, engraved look, such as multi-level three-dimensional sculpture, make the content more rich thick, Mosaic image is more vivid and full, tao to spend, wear a terrier, flexible smooth (see figure 8). Specific divided into wood carvings, stone carvings and brick carvings, stone carving decoration techniques skillfully, stone carving decoration techniques in carving, engraving, cutting, etc in order to make a graven image finer, smooth and supplemented by means of polishing abrasive. As the local-style dwelling houses and ancestral temple in the ancient site pillars, stone plaques, and wall act the role ofing, etc. Act the role of plaque and wall act the role ofing use hollow out valuable.such handiwork, that is, on the basis of the deep anaglyph further sculpture, some still with the borders, expression of of primitive simplicity, gorgeous beauty, also reflected the jingdezhen ancient site construction decoration technology exquisite. Brick carvings art by way of joining together, joining together the images of the characters, flowers design embodies the craftsman knife skills. Such as the ancestral temple door head brick carvings.

\section{Jingdezhen ancient kiln heritage landscape design}

In the cultural change and the progress of the society under the background of the Jingdezhen ceramic production technology innovation, porcelain making architectural landscape unfolding. This kind of ceramic production and the natural environment, the interaction between interdependence and mutual influence, has created the characteristics of the traditional Jingdezhen porcelain making architectural landscape system. Jingdezhen traditional workshop and kiln landscape architecture embodies the ecological, social and cultural blend a few people in the world.

Construction on the natural environment of the landscape pattern, forest resources, climate condition, the construction of workshop and kiln room make full use of the topography of jingdezhen, formed the clever space construction pattern, forest mineral resources for ceramic production provide sufficient fuel, raw materials, etc.; Craftsmen according to the growth cycle of firewood and reasonable plan, pine, Wolf broom fuels such as cut down the time, after processing by the river, streams drift all the way to the workshop, again by handling, packed workshop craftsmen in preparation for the kiln firing porcelain; China stone, porcelain clay, glaze fruit such as raw materials by water to the workshop, the largest extent, alleviate the intensity of labor and transportation costs; Kiln (bank kiln is the most significant) built in accordance with the slope, which make full use of the slope of the mountain, and do not take up residents living space, do the rational use of the 
environment space. Jingdezhen ceramic product reuse with waterway transportation sales across the country and around the world, make up one of the wonders of Jingdezhen porcelain.

Natural resources is not the only condition of ceramic production, ceramic culture, porcelain making technology, folk customs, ideas and so on also affects the development of the innovation system of jingdezhen traditional porcelain workshop, kiln room building landscape pattern, such as workshops, the construction location, spatial layout, construction of kiln room adornment style is influenced by local cultural factors, it is the special natural environment and humane environment achievement the jingdezhen unique porcelain making the history of landscape architecture.

\section{Jingdezhen Ceramic Mill and the Architectural Art}

People according to specific geographical conditions creating unique bearing the particularity of the landscape, landscape of landscape pattern or specific patterns of behavior, conventions, concentrated on the characteristics of ecosystem function. Such as the structure of the jingdezhen porcelain making workshop, layout, the four seasons is according to the local subtropical humid climate, perfectly with the relationship between ecological environment and construction methods: ventilation and avoid dust; Daylighting, and shelter; Keep warm and cold weather.

Jingdezhen ceramic mill has many advantages, simple construction, wood materials, to the nearest from disused kiln brick masonry wall, save time and effort, save resource and low cost, the factory of the rainy day or courtyard structure, is conducive to each working procedure, assembly-line production and convenient centralized management; Full house sits, sunshine time, the light is good for bad body dry, warm in winter and cool in summer, for craftsmen to build the comfortable environment of porcelain manufacture; Process layout is reasonable, compact, to make full use of space, convenient craftsmen.

Architectural art is a kind of practical art, and closely linked with people's life and social production, its primary purpose lies in practical function, but also to meet people's aesthetic requirements, is the unity of technology and art. Workshop of aesthetic value is mainly manifested in the structure design aesthetic. Architecture is practical, regional characteristics, technical wood, in the design of traditional Jingdezhen porcelain making workshop building has been fully reflected, and especially the practicability of workshop building, regional and technical has its special artistic value.

Workshop decoration not Jingdezhen as other ancient buildings (such as the ancestral hall, hall) as decorative style, the building decoration is the brick, stone, tile, gray material such as natural color. Workshop front door is eight, top with a mountain wall head, build by laying bricks or stones becomes ChiWei bead. Roof of the central tend to form various kinds of auspicious patterns in brick and tile, water droplets, gable, Windows, the detail processing of cross-bars personality is distinct, with kindness, sequence of feeling on the vision. Whole fang to send building characteristic: white wall tiles, symmetry, neat, closed, architectural form and regional landscape be in harmony for - and body. Jingdezhen embodies the unique national style. As well as the construction decoration technology and the perfect combination of natural ecology.

Traditional workshop building space form beauty in summary is mainly manifested in its portfolio construction of harmony and symmetry. Harmony embodied in the workshop of the axially symmetric layout and the architectural layout, workshop things vertical line as axis, the body of the workshop construction, are arranged in the axis between the north and the south between the symmetrical position for Ao, mud is placed in the east room, make the whole building harmonious, stable and has a sense of order. Formed a unique features "axis" the beauty of architecture form. The whole building exterior plain, vigorous; Reasonable arrangement of space. And in the process of the structure, function needs to have a focus on balance, stability and security.

Architectural technology innovation is a driving force of the architectural form evolution, is the perfect combination of art and technology. The beauty of Jingdezhen traditional workshop construction technology is very typical and unique. Its building materials fully confirms the concept of adjust measures to local conditions, due to the carvers, the use of local rich timber resources and 
abandoned brick kiln, sagger, bread, backfilling industrial wastes such as construction, decoration workshop, truly the low energy consumption, high efficient construction technique. Reflects the "nature and humanity, ecology, formed of Jingdezhen building unique aesthetic value.

\section{Environment Friendly Material used in Jingdezhen Architectural}

Jingdezhen porcelain making workshop building process using non-polluting, renewable natural materials, nearby materials, and will be in the production of waste water, waste recycling, using scrap kiln brick masonry wall, reduce building energy consumption, on the basis of guarantee the comfort and improve the heat preservation, heat insulation performance of the workshop, at the same time increase the use of energy, maximize the use of solar energy, wind energy and natural rain, improve the efficiency of heating, ventilation. Jingdezhen craftsmen according to the ceramic production process and complex nature of workshop layout reasonable space scales, make processes all interlocking, shortest distance. Embodies the Jingdezhen ceramics workshop unique architectural concept, to achieve the perfect system of the function, structure, style, and is one of the classics of man and nature in harmony.

The evolution of Jingdezhen ceramic workshops, illustrates the geographical change during the period of historical relationship with the social progress. Ceramic dust is produced depends on natural ecology, the rise and development of changing the environment, can reflect the human and the nature is the most interactive handicraft, different natural and humanistic environment makes the local characteristics of ceramic production technology, particularly suitable for the theoretical perspective of human geography. Jingdezhen ceramic workshop landscape, with the harmony of ecological, social, industry, jingdezhen ceramic production, relies on natural landscape pattern of the traditional resources, forest provide enough fuel for ceramic production, mineral feldspar, kaolin clay, glaze for ceramic production fruit, etc.; Rivers provide ceramic production water not only, still can provide the fuel, raw materials, ceramic products sales of transportation, to maintain the ceramic production system energy flow and material balance, has the unique function.

People according to specific geographical conditions creating unique landscape carries the particularity of the landscape. Show the landscape pattern or specific behaviors, customs. Landscape elements of traditional Chinese architecture and culture, geography, natural factors mutual confluence, has the characteristics of cultural ecology and human relationships, such as the structure and function of jingdezhen ceramic porcelain workshop, the four seasons is according to the local subtropical humid climate, perfectly with the ecological environment and process technology, physical changes and the relationship between ecological changes: reasonable layout workshop structure according to the particularity of ceramic technology, perfectly coordinated research architectural space and technology.

In Jingdezhen porcelain making workshop has a strong, practical, beautiful, economic and efficient characteristics. Strong, practical is the foundation. It is a human means against environmental climate, according to the jingdezhen subtropical monsoon climate, building sits in the workshop, can at the same time in the summer to avoid strong western avoid daylighting is insufficient; Can stop the northwest wind in winter again the damage to the body. Aesthetics refers to the part on the very roof of the workshop, cross-bars deco make workshop appearance give a person visual enjoyment and spiritual pleasure.

\section{Conclusion}

From what has been discussed above. Traditional jingdezhen porcelain making workshop is one thousand which is made porcelain culture and an important part of practical experience, jingdezhen ceramic culture exists in the whole ecological landscape pattern, reflecting the relationship between landscape pattern and ecological environment and its scale conversion, is in the air, the category, quantity, structure, and sequence on the interaction of people constantly improve the mechanism of the ecological landscape, namely the nature forms, realize ecological efficiency and social 
effectiveness are consistent, to achieve a high degree of unity of economic development and environmental protection. At the same time embodies the Jingdezhen craftsmen fully adapt to the local natural environment and humane environment makes sustained Jingdezhen special regional culture. Jingdezhen in long-term production of porcelain manufacture practice, create the traditional handmade porcelain workshop. Either plane or space have been making full use of, sufficient to meet the hand round porcelain making production needs, embodies the wisdom of Jingdezhen artist and the unity of nature and design thought.

\section{Acknowledgments}

This work was financially supported by: 1, Jiangxi social sciences planning project of the intangible cultural heritage tourism landscape design research - Jingdezhen ancient kiln heritage tourism landscape, for example, the number is: 15 ys27. 2, in Jiangxi province cultural department scientific research project of the Jingdezhen culture industry construction under the ancient site of the landscape design research, number is: YG2014177. 3, humanities and social science in colleges and universities in Jiangxi province project the regionality of humanities landscape design - to Jingdezhen ancient kiln building landscape design as an example, and Numbers for: GX201529

\section{References}

[1] lixin li "the design of art research methods" nanjing: jiangsu phoenix publication medium group fine arts publishing house, 2010.

[2] Various ge armoured with "design art ten speak" jinan: shandong pictorial publishing house, 2006.

[3] liang sicheng "Chinese architecture" Beijing: China building industry press, 2005.

[4] Dai Wu three "the well after the Jinan: Shandong pictorial publishing house, 2005.

[5] Chang Huaisheng building environment psychology, Beijing: China building industry press, 1990.

[6] Liu Duizhen "Chinese ancient architectural history" Beijing: China building press, 2001.

[7] xiu-mei wu "system of inheritance and change: the republic of China jingdezhen porcelain development research, Beijing: guangming daily press, 2012.

[8] Chen were compiled "Chinese ceramic culture" Beijing: China building industry press, 2004. 